\title{
Preparation of calcium alginate-encapsulated sulfur particles and their application in metal nanoparticle capture: A case study of silver nanoparticles
}

\author{
Koon Ming Lee ${ }^{\mathrm{a}}$, Wei Chuen Yoong ${ }^{\mathrm{a}}$, Chui Fung Loke ${ }^{\mathrm{a}}$, Joon Ching Juan ${ }^{\mathrm{b}}$, Khatijah Yusoff ${ }^{\mathrm{c}}$, \\ Norhafizah Mohtarrudin ${ }^{\mathrm{d}}$, Teck Hock Lim ${ }^{\mathrm{a}, *}$ \\ ${ }^{a}$ Faculty of Applied Sciences, Tunku Abdul Rahman University College, Kuala Lumpur 53300 Malaysia \\ b Nanotechnology \& Catalysis Research Centre, University of Malaya, Kuala Lumpur 50603 Malaysia \\ c Faculty of Biotechnology \& Biomolecular Sciences, Universiti Putra Malaysia, Serdang 43400 Malaysia \\ ${ }^{d}$ Faculty of Medicine \& Health Sciences, Universiti Putra Malaysia, Serdang 43400 Malaysia
}

*Corresponding author, e-mail: limth@tarc.edu.my

Received 11 Nov 2020

Accepted 15 Feb 2021

\begin{abstract}
Uniform anisotropic sulfur particles of $5.5 \pm 0.4 \mu \mathrm{m}$ in length, $3.9 \pm 0.4 \mu \mathrm{m}$ in width/thickness and an aspect ratio of 1.4 were successfully synthesized for the first time via the reaction of thiosulfate with a weak acid in the presence of sodium alginate which acted as a surfactant to impart water dispersibility and bestow particle size control. The sulfur particles with a zeta potential measured to be $-29.5 \mathrm{mV}$ were structurally characterized using PXRD and FESEM. After purification, the alginate-protected sulfur particles were discharged into a calcium chloride solution to produce fibrous calcium alginate-encapsulated sulfur composite (Ca-Alg-S) via ionotropic gelation. Ca-Alg-S was tested as absorbent of silver nanoparticles (Ag NPs) and compared to Ca-Alg gel absorbent. The Ag NPs were produced using sodium alginate as both surfactant and reducing agent under microwave-assisted heating to ensure the effect of surfactant on Ag capture was minimized. The effect of contact time on the removal efficiency of Ag NPs was established by tracking the decreasing absorbance of Ag NPs at $400 \mathrm{~nm}$ which was due to the surface plasmon resonance (SPR) band of Ag NPs of 10-20 nm in size. As high as 90\% of Ag NP capture efficiency was achieved using Ca-Alg-S within $8 \mathrm{~h}$ under ambient conditions. The application of Ca-Alg-S may be extended in the future to other heavy metals including $\mathrm{Hg}, \mathrm{Cd}, \mathrm{Ni}$ and $\mathrm{Pd}$ which are known to react readily with sulfur, allowing effective wastewater treatment without the use of toxic sulfide or costly nanofiltration system.
\end{abstract}

KEYWORDS: sulfur particles, alginate-gel-encapsulation, Ag nanoparticle removal, capture efficiency

\section{INTRODUCTION}

In recent years, silver nanoparticles (Ag NPs) have been used worldwide in numerous applications across a variety of fields owing to their unique size-dependent chemical, biological and physical properties [1-4]. Ag NPs may be found in many household products including antibacterial fabrics, fridges, detergents, cosmetics and food packing materials [5-8]. The release of Ag NPs into the environment during the lifecycle of consumer products containing Ag NPs is therefore considered inevitable [8-11]. For example, Benn and Westerhoff showed that the leaching of Ag NPs and ionic Ag from six commercially available Ag NPs-embedded socks did occur readily during washing with only water [11]. The presence of Ag NPs in the environment could potentially harm and damage the eco-system by inducing toxicity to the aquatic organisms and phytotoxicity to plants after being accumulated in soils and water bodies $[8,12,13]$. In 2018, Abramenko et al demonstrated the detrimental effects of nanosilver on the embryos of zebrafish (Danio rerio) while Horng et al concluded that Ag NPs impaired the learning and social behaviors of adult zebrafish $[14,15]$. Ag NPs with smaller sizes overall have a higher tendency to enter into cells and to disturb the normal cell machinery from working efficiently [4]. Ag NPs as small as $15 \mathrm{~nm}$ could produce more reactive oxygen species (ROS) in the concentration range of $0-75 \mu \mathrm{g} / \mathrm{ml}$ which is capable of inducing severe damage to the mitochondrial membrane structure and incurring mitochondriadriving cell death [16]. Furthermore, over an extended period of time, the oxidative activity of $\mathrm{Ag}$ NPs may release $\mathrm{Ag}^{+}$ions which are known to 
bring about adverse effects on biological systems by inducing cytotoxicity, genotoxicity, immunological responses and even cell death $[17,18]$.

To tackle the issues of Ag NP waste and subsequent pollution, researchers worldwide have worked collectively, and several methods including aeration, coagulation and adsorption have been studied for the removal of Ag NPs during wastewater treatment $[8,19-21]$. The aeration method is the most complicated amongst the three methods because it requires the use of sequencingbatch-reactors and is relatively time-consuming to operate $[8,22]$. For coagulation method, the toxic coagulants such as ferric chloride, polyferric sulfate and polyaluminium chloride used in the process might themselves become pollutants after wastewater treatment [2,23]. Removing $\mathrm{Ag}$ NPs from water using adsorption method which includes nanofiltration is considered a preferred method for it is safer and simpler while free from the use of toxic coagulants [2]. Owing to this positive attribute, the suitability of different synthetic, commercial and natural materials such as nanoscaled poly(amic acid) [nPAA], electrolyteinfused activated carbon (Norit ${ }^{\circledR}$ CA1), dopamine or glutathione coated magnetic nanoparticles and tetraethylenepentamine modified silica have been intensively investigated as adsorbents [22-24]. According to McGillicuddy et al, the capture of Ag NPs becomes more problematic when the particle size become exceedingly smaller [22] and the use of conventional membrane filters is not workable because their pore sizes exceed the dimensions of Ag NPs. Additionally, fabricated membranes may be inconsistent in terms of pore size distribution which means certain portion of extremely small Ag NPs can still pass through the filters [24]. Furthermore, the current nanofilter technology requires high capital cost, and it is also relatively challenging to recover $\mathrm{Ag}$ NPs as a precious metal from the filters without destroying the costly filters $[25,26]$.

On a separate note, a simple adsorbent preparation method such as ionotropic gelation technique has been useful for encapsulating nanoparticles, proteins and others including chitosan [27-29]. Along with the increasing incidences of Ag NPs being leached into the environment through wastewater stream and effluent [22], as well as the reported adverse environmental impacts of Ag NPs [15-19], there is a pressing need to develop a green, simple method for the removal of Ag NPs from wastewater using only non-toxic, low-cost absorbent materials. The end product after treatment should also allow easy recovery of Ag.

To the best of the author's knowledge, the use of elemental sulfur encapsulated in calcium alginate gel as adsorbent for Ag NPs has not been previously reported. In this work, the aim was to develop a new facile method for the preparation of uniform sulfur particles under ambient conditions via the reaction of thiosulfate and a weak acid. Sodium alginate was used as a surfactant to control particle size, impart water dispersibility and assist in the later ionotropic gelation step with calcium salt to produce calcium alginate-encapsulated sulfur particle (CaAlg-S) adsorbent materials. The capture efficacy was tracked with UV-Vis spectroscopy under static condition, following the characteristic SPR band of $10-20 \mathrm{~nm}$ Ag NPs centered at $400 \mathrm{~nm}$.

\section{MATERIALS AND METHODS}

\section{Chemicals}

Unless otherwise mentioned, chemicals used were of analytic grade. Silver nitrate $\left(\mathrm{AgNO}_{3}\right)$ and sodium alginate were purchased from SigmaAldrich, and sodium thiosulfate pentahydrate $\left(\mathrm{Na}_{2} \mathrm{~S}_{2} \mathrm{O}_{3} \cdot 5 \mathrm{H}_{2} \mathrm{O}\right)$ and calcium chloride-dihydrate $\left(\mathrm{CaCl}_{2} \cdot 2 \mathrm{H}_{2} \mathrm{O}\right)$ were sourced from Systerm. Potassium chloride from Bendosen Laboratory Chemicals was used for calibration of chloride standard solutions. All chemicals were used without further purification.

\section{Sulfur particle synthesis}

Five grams of sodium thiosulphate was dissolved in $200 \mathrm{ml}$ of distilled water to which $30 \mathrm{ml}$ of $3 \% \mathrm{w} / \mathrm{v}$ sodium alginate solution was added slowly, followed by 5 min of mixing. Next, the solution was topped up to $500 \mathrm{ml}$ with distilled water, and $2.5 \mathrm{ml}$ of a weak acid solution was added. The mixture was stirred for $2 \mathrm{~h}$ under ambient conditions.

\section{Calcium alginate-encapsulated sulfur particle fibrous gel (Ca-Alg-S)}

Synthesized sulfur particles were purified through centrifugation at $6000 \mathrm{rpm}$ at $4^{\circ} \mathrm{C}$ for $15 \mathrm{~min}$ to remove by-products. The isolated sulfur particles were redispersed in $20 \mathrm{ml}$ of $3 \% \mathrm{w} / \mathrm{v}$ sodium alginate solution to form a homogenous solution which was then discharged from the burette into $200 \mathrm{ml}$ of $2 \mathrm{M}$ aqueous $\mathrm{CaCl}_{2}$ to produce $\mathrm{Ca}$ Alg-S (see Supporting Information). Ca-Alg-S was washed with $100 \mathrm{ml}$ of distilled water and shaken at $150 \mathrm{rpm}$ for $10 \mathrm{~min}$ using a MDL DK-0510 orbital shaker. Next, the aqueous solution was collected 
and filtered using a $0.22 \mu \mathrm{m}$ syringe filter, and the residue chloride concentration was determined using Ion Chromatography (Dionex ICS-1000) after calibration. The washing process was repeated until no chloride anion was detected in the collected solution. The average diameter of Ca-Alg-S was obtained using a Mitutoyo High-Accuracy Sub-Micron Digimatic Micrometer.

\section{Calcium alginate fibrous gel (Ca-Alg)}

Ca-Alg was prepared by employing the method used to prepare Ca-Alg-S described above but with the absence of sulfur particles.

\section{Microwave-assisted synthesis of Ag NPs}

Alginate-stabilized silver nanoparticles were synthesized according to a literature method described in [35]. First $0.068 \mathrm{~g}$ of silver nitrate was dissolved in $10 \mathrm{ml}$ of distilled water, and $1 \mathrm{ml}$ of the $10 \mathrm{ml}$ solution was taken to mix with $20 \mathrm{ml}$ of $0.5 \% \mathrm{w} / \mathrm{v}$ sodium alginate solution in a borosilicate $\mathrm{G} 30$ vial. Then the mixture was heated to $180^{\circ} \mathrm{C}$ for $2 \mathrm{~min}$ using a microwave reactor (Anton Paar Monowave 400). The formation of Ag NPs was monitored by observing the colour change captured every $15 \mathrm{~s}$ by a digital camera integrated to the microwave reactor.

\section{Ag NP capture by Ca-Alg-S and Ca-Alg}

Five grams of Ca-Alg-S and Ca-Alg were packed into the bottom of two respective columns. Ag NPs from different batches of synthesis over 2 weeks were combined and mixed, mimicking those found in the wastewater without matrix effect. The initial absorbance of the Ag NP solution was measured. For the time series study, $20 \mathrm{ml}$ of Ag NP solution was loaded into each column and eluted at a flow rate of $2.9 \mathrm{ml} / \mathrm{s}$ at a 10-min interval up to a total of $80 \mathrm{~min}$. The set-up for the 8 -h study was the same but without any liquid drained apart from the 0-h and 8-h contact sampling time.

\section{Characterization}

Powder X-ray diffraction (PXRD): An X-Ray diffractometer (PANalytic Empyrean, United Kingdom) with $\mathrm{Cu} \mathrm{K \alpha}(\lambda=1.5404 \AA)$ operating at $45 \mathrm{kV}, 40 \mathrm{~mA}$ and $25^{\circ} \mathrm{C}$ was used to carry out phase identification of the sample. The scanning range was $20-80^{\circ} \mathrm{C}$ with a step size of $0.026^{\circ}$. Degree was measured as $2 \theta$ degree.

Field emission scanning electron microscopy (FESEM): A CFE-SEM (Hitachi SU8230, Japan) operating at $2.0 \mathrm{kV}$ was used to study the sulfur particles produced. Samples were air-dried on silicon wafers at room temperature after sonication to disperse and ensure uniformity.

Zeta potential measurement: A particle analysis instrument (Anton Paar Litesizer 500, Austria) operating at $200 \mathrm{~V}$ and $25^{\circ} \mathrm{C}$ was used to carry out zeta potential measurements using a laser of $658 \mathrm{~nm}$. Samples were measured by averaging 1000 runs per reading with the refractive index of water used. Measurements were in compliance with ISO 13099-2 2012 as stated by the manufacturer. An average of four readings was taken as the representative zeta potential value for each sample.

UV-Vis absorption: A UV-Vis spectrophotometer (Hitachi U-2900, Japan) was used to determine the concentration of Ag NPs via maximum absorbance at $400 \mathrm{~nm}$ (SPR of Ag NPs) after calibration. For calibration, five different concentrations (0.1$2.0 \mathrm{mg} / \mathrm{ml}$ of $\mathrm{Ag}$ NPs) were used with a linear trendline and obtained a $R^{2}$ of 0.9998 .

\section{RESULTS AND DISCUSSION}

\section{Sulfur particle preparation}

Highly crystalline sulfur particles of $5.5 \pm 0.4 \mu \mathrm{m}$ in length with an average aspect ratio of 1.4 were successfully produced from the facile disproportionation reaction of thiosulfate under acidic conditions [30]. For the first time, sodium alginate was employed as a surfactant to bestow particle size control, dispersibility and colloidal stability in water.

As shown in Fig. 1(a), the sulfur particles produced were uniform in size with a standard deviation of $0.4 \mu \mathrm{m}$ or $7 \%$ in length (measured along $c$ axis as shown in Inset Fig. 1(a) and Fig. S1). Width and thickness were measured at $3.9 \pm 0.4 \mu \mathrm{m}$, giving an average aspect ratio of 1.4. The uniquelyshaped particles were similar in shape with distinct facets readily observed, and the particles adopted the shape of an orthorhombic combined form with the $\{111\}$ and $\{113\}$ facet family exposed (see Inset Fig. 1(a)). Sulfur is well-known to be strongly hydrophobic, and the use of sodium alginate in this work helped overcome the dispersibility issue. A zeta potential value of $-29.5 \mathrm{mV}$ (see Fig. 1(b)) imparted by the negative carboxylate groups of alginate surfactant bestowed the sulfur particles with excellent water dispersibility, evidenced by the uniform milky dispersion shown in the Inset of Fig. 1(b). The crystallinity of the sulfur is high because sharp diffraction signals were observed 

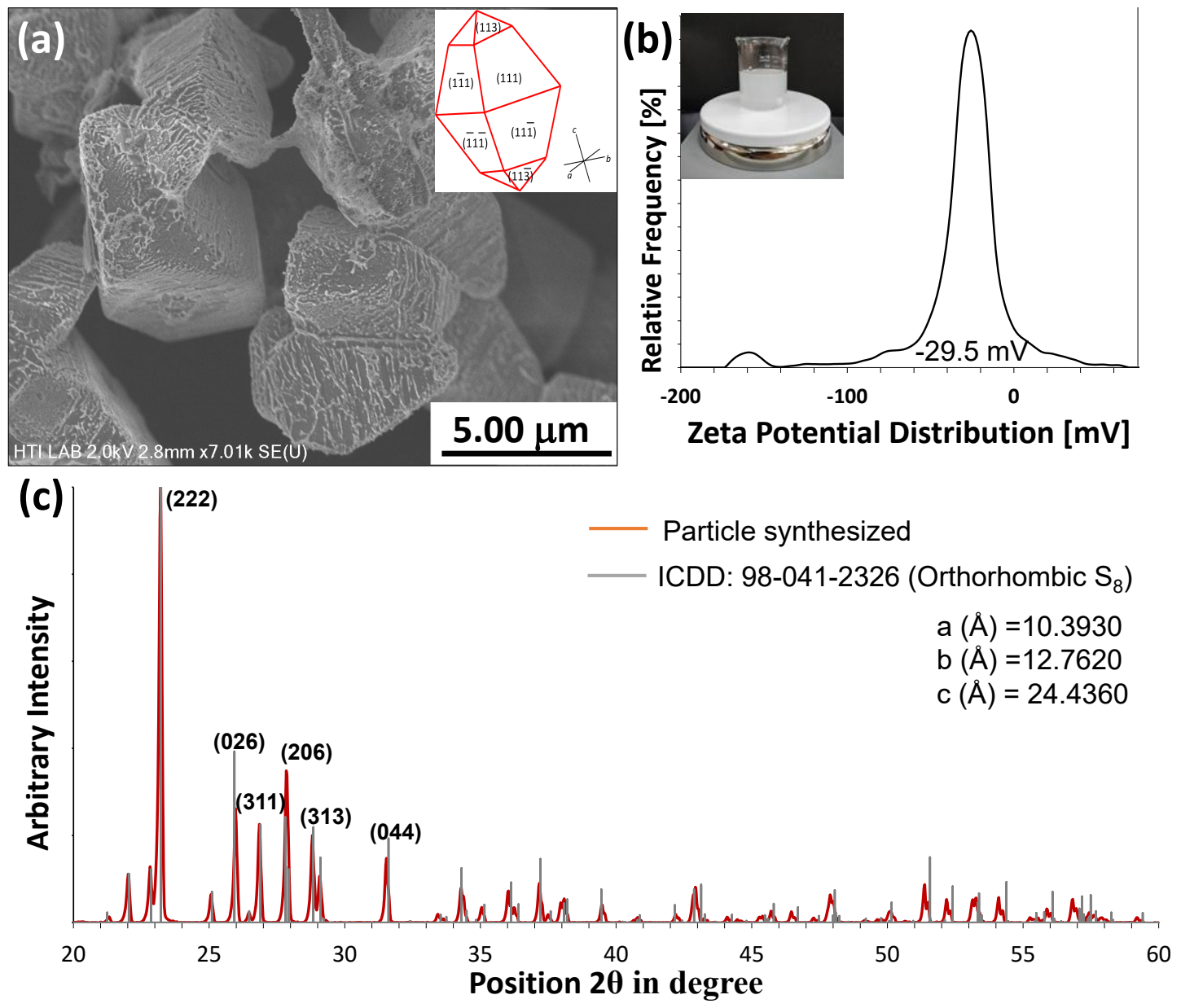

Fig. 1 Characterization of sulfur particles produced from controlled acidification of thiosulfate using sodium alginate as a surfactant. (a) FESEM image showing sulfur particles with a narrow size distribution $(5.5 \pm 0.4 \mu \mathrm{m}$ in length and 3.9 $\pm 0.4 \mu \mathrm{m}$ in width/thickness and an average aspect ratio of 1.4); (b) Zeta potential of sodium alginatestabilized sulfur particles measured at $-29.5 \mathrm{mV}$ translates to good colloidal stability. Inset shows a white uniform colloidal suspension of the as-synthesized sulfur particles; (c) PXRD analysis showing sample produced, well-matched to orthorhombic $\mathrm{S}_{8}$. Major diffraction signals in the diffractogram labelled with respective Miller indices.

across the XRD diffractogram (see Fig. 1(c)), and the phase was identified to be orthorhombic sulfur by matching to the standard ICDD 98-041-2326 for orthorhombic sulfur with a formula of $\mathrm{S}_{8}$.

The target size of sulfur particles produced in this work was to be in near 5 micrometers for the three reasons below: (1) literature works have collectively pointed out that sulfidation of Ag NPs via sulfide $\left(\mathrm{S}^{2-}\right)$ and acid volatile sulfide (AVS) is limited by the sulfur bearing counterpart and the size of Ag NPs [31,32]. Sulfur particles of $5 \mu \mathrm{m}$ in size (i.e. $5000 \mathrm{~nm}$ ) are significantly larger than Ag NPs $(1-100 \mathrm{~nm})$, and in theory there is sufficient sulfur counterpart for sulfidation to occur rapidly during the capture of Ag NPs, avoiding the situation of having insufficient sulfur as reported by Kaegi et al and Reinsch et al [31, 32]; (2) micron-sized particles are considered safer when exposed to human bodies as the particles cannot pass through the physical barriers as easier as the much smaller nanoparticles [33]; (3) $5 \mu \mathrm{m}$ is the preferred particle size for vulcanization of rubber in the rubber industry, and we anticipate that the sulfur particles reported here may be useful [34]. To further enhance the safety and ensure aqueous Ag NPs could interact well with the sulfur particles, the micron-sized sulfur particles synthesized were encapsulated in a calcium alginate hydrogel by means of extruding a suspension of sulfur in $3 \%$ sodium alginate into calcium chloride solution for ionotropic gelation to occur (see 
Fig. S2).

\section{Microwave-assisted synthesis of Ag nanoparticles}

To investigate the suitability and efficacy of $\mathrm{Ag}$ NP capture/removal using the sulfur particles produced, uniform Ag NPs were first synthesized following a literature method in which sodium alginate was used as both reducing agent and surfactant [35]. This synthesis allowed a one-pot synthesis of $10-20 \mathrm{~nm} \mathrm{Ag} \mathrm{NPs} \mathrm{rapidly.} \mathrm{It} \mathrm{is} \mathrm{considered}$ green because there was no stoichiometric waste produced as in the case of using $\mathrm{NaBH}_{4}$ as reducing agent [36].

Fig. 2 showed that the produced Ag NPs exhibited a surface plasmon resonance (SPR) band centred at $400 \mathrm{~nm}$. The same SPR value was reported in the literature from which the method was chosen, indicating Ag NPs of $10-20 \mathrm{~nm}$ were produced $[35,36]$. The inset in Fig. 2 is a time series collection of photos of the reacting mixture. A noticeable colour change started after $15 \mathrm{~s}$ of heating, and the growth of Ag NPs was evidenced by the intensifying yellow-brown colour over the $120 \mathrm{~s}$ of microwave heating. Microwave-assisted synthesis is known to produce uniformly sized nanoparticles due to its capability to rapidly and uniformly heat a reaction mixture which was observed in Fig. 2 [37].

The formation of Ag NPs involved the reduction of $\mathrm{Ag}^{+}$ions which were first bonded to the carboxylate groups of the alginate. Due to $\mathrm{Ag}^{+}$is singly-charged, no gelation occurred. During the microwaving process, hydroxyl groups on the $\beta$-DMannuronic acid (M) and $\alpha$-L-guluronic acid (G) were oxidized into alginate di-aldehyde while $\mathrm{Ag}^{+}$ reduced to nascent $\mathrm{Ag}^{0}$ which then grew into $\mathrm{Ag}$ NPs $[36,37]$. The carboxylate groups of alginate stabilized the Ag NPs and prevented them from coalescence via means of electrostatic repulsion and steric hindrance effects. Having alginate as the only surfactant helped avoid potential interference of surfactants during the Ag NP capture experiments involving the use of calcium alginate and calcium alginate-encapsulated sulfur described in the next section.

\section{Preparation of calcium alginate fibrous gel (Ca-Alg) and calcium alginate-encapsulated sulfur particle fibrous gel (Ca-Alg-S)}

Ca-Alg-S with a $27 \%$ wt sulfur particle loading was produced via ionotropic gelation as described in Materials and Methods section. Across the range of concentration tested $\left(0.5 \mathrm{M}, 1 \mathrm{M}\right.$ and $\left.2 \mathrm{M} \mathrm{CaCl}_{2}\right), 2$
$\mathrm{M}$ concentration was found to produce Ca-Alg and Ca-Alg-S with firmness that allowed easy handling. Ca-Alg and Ca-Alg-S produced were washed with distilled water until no chloride was detected in the effluent. The presence of chloride ions is known to enhance the dissolution of Ag NPs and capable of altering the shapes of Ag NPs, thus likely to affect the UV-Vis absorption properties of Ag NPs [38]. To ensure that chlorides are not interfering with our Ag NP capture study, it is critical that the $\mathrm{Cl}^{-}$ions are removed from Ca-Alg-S and Ca-Alg. Chloride removal was confirmed through the use of Ion Chromatography (Dionex ICS-1000) after vigorous calibration (see Fig. S3). The dimensions and properties of CaAlg-S and Ca-Alg are summarized in Table 1.

\section{Ag NP capture by Ca-Alg-S and Ca-Alg}

As shown in the inset of Fig. 3, Ag NPs of known concentration were treated with a known amount of Ca-Alg-S, and the removal/capture of Ag NPs was tracked by observing the decreasing absorbance at $400 \mathrm{~nm}$ which is the SPR signal of the synthesized Ag NPs. The capture efficacy was quantified using Eq. (1) where $A_{\mathrm{i}}$ is the initial absorbance of Ag NP solution at $400 \mathrm{~nm}, A_{\mathrm{f}}$ is the final absorbance of $\mathrm{Ag}$ NP solution at $400 \mathrm{~nm}$ and $A_{\mathrm{b}}$ is the absorbance of method blank solution at $400 \mathrm{~nm}$. The concentration of $\mathrm{Ag}$ was correlated to absorbance after a successful calibration (see Fig. S4). Fig. 3 showed a rapid decrease in absorbance at SPR band centered at $400 \mathrm{~nm}$ over a total of $80 \mathrm{~min}$ of contact time with absorbance measured at a constant interval of $10 \mathrm{~min}$, and $55 \%$ of Ag NPs were captured within $80 \mathrm{~min}$. The broadening and increase of absorbance at $550 \mathrm{~nm}$ are attributed to the absorption of $\mathrm{Ag}_{2-\mathrm{x}} \mathrm{S}$ formed after capture [39].

$$
\% \text { Capture }=\frac{\left(A_{\mathrm{i}}-A_{\mathrm{b}}\right)-\left(A_{\mathrm{f}}-A_{\mathrm{b}}\right)}{\left(A_{\mathrm{i}}-A_{\mathrm{b}}\right)} \times 100
$$

The affinity of $\mathrm{Ag}$ towards $\mathrm{S}$ played an important role in the effective and rapid removal of Ag NPs observed in Fig. 3 through the formation of nonsoluble $\mathrm{Ag}_{2-\mathrm{x}} \mathrm{S}$. As a precious metal, $\mathrm{Ag}$ could be recovered from the end product $\mathrm{Ag}_{2-\mathrm{x}} \mathrm{S}$ trapped in Ca-Alg-S more readily when compared to the recovery of Ag NPs caught in nanofilters. Sulfidation of Ag NPs was known to be limited by the diffusion of sulfur species as reported for $\mathrm{S}^{2-}$ and acid volatile sulfide (AVS) [31,32]. By having a $5 \mu \mathrm{m}$ sulfur particles, which are $\sim 500$ times larger than a $10-\mathrm{nm}$ $\mathrm{Ag}$ NP, the first step likely involved rapid anchoring of Ag NPs on sulfur followed by sulfide diffusion. 


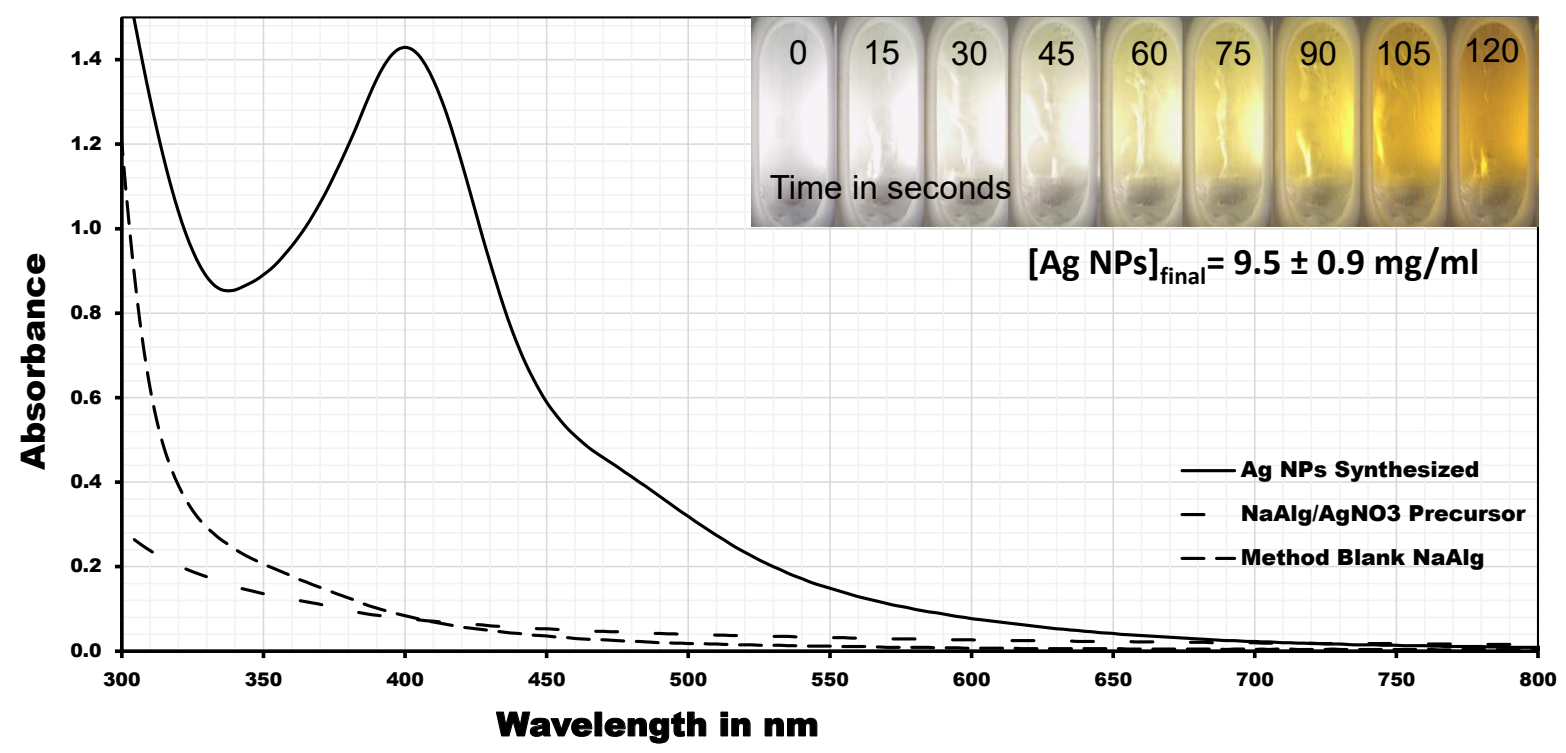

Fig. 2 Microwave-assisted synthesis of $\mathrm{Ag}$ nanoparticles from $\mathrm{AgNO}_{3}$ and sodium alginate. The end product has a sharp absorption maximum centred at $400 \mathrm{~nm}$, corresponding to the SPR of Ag NPs of size 10-20 nm. The inset showed realtime images of the reacting mixture captured over $120 \mathrm{~s}$ of reaction time. The formation and presence of Ag NPs are consistent with the observations reported in [35]. Na-alginate (Na-Alg) and a mixture of Na-Alg and $\mathrm{AgNO}_{3}$ did not exhibit any noticeable absorption over the $300-800 \mathrm{~nm}$ range.

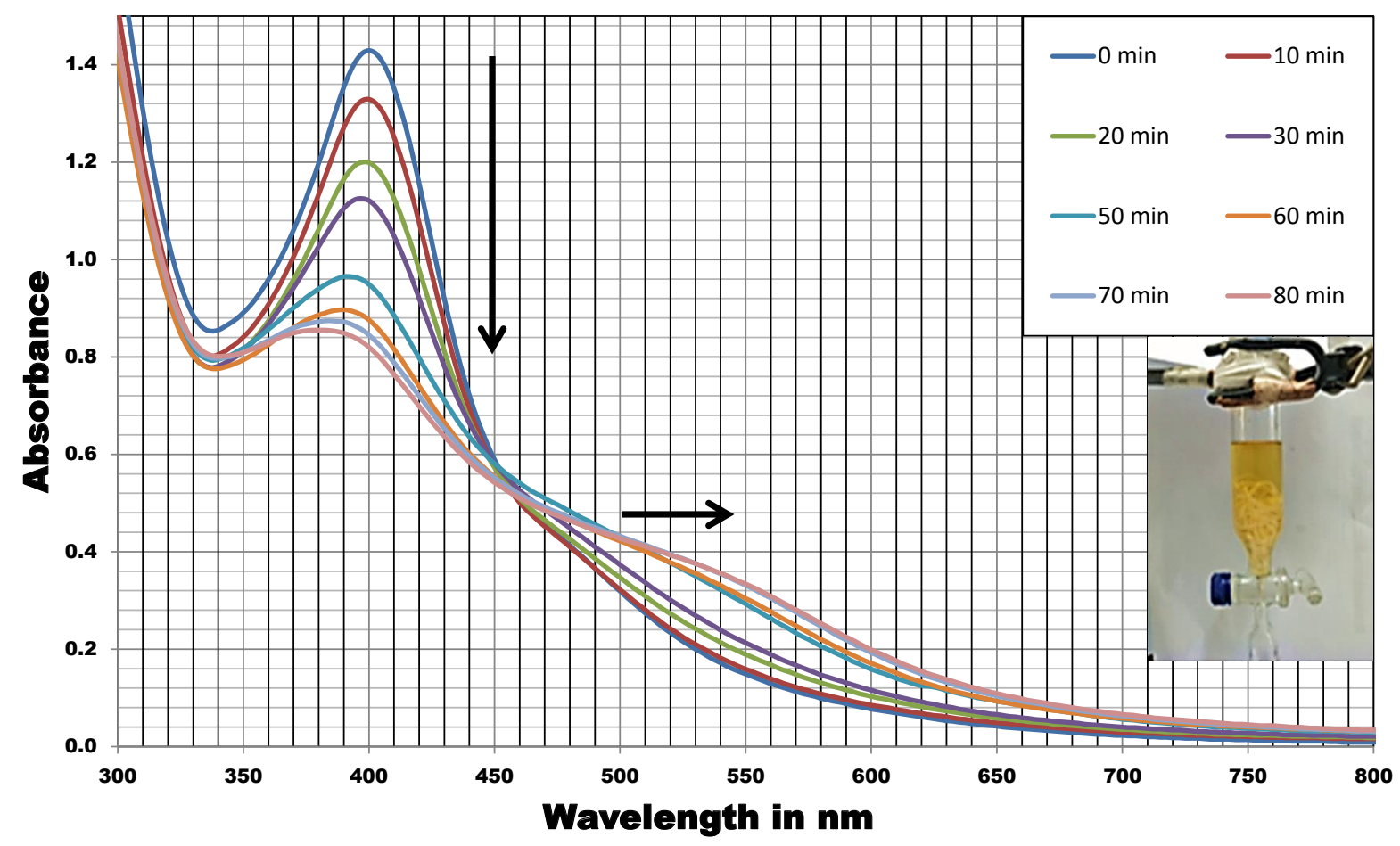

Fig. 3 Real-time tracking of capture of Ag NPs by Ca-Alg-S. The absorbance intensity at $400 \mathrm{~nm}$ (SPR band of 10-20 nm $\mathrm{Ag}$ NPs) reduced to $55 \%$ after $80 \mathrm{~min}$, and the capture of Ag NPs seemed to follow an almost linear decreasing trend via the reaction of $\mathrm{Ag}$ and S particles. The UV-Vis spectra became broadened, and the absorbance at $550 \mathrm{~nm}$ increased in intensity overtime. The increase observed at $550 \mathrm{~nm}$ was attributed to the absorption of visible light as a result of sulfidation of Ag by sulfur particles. 


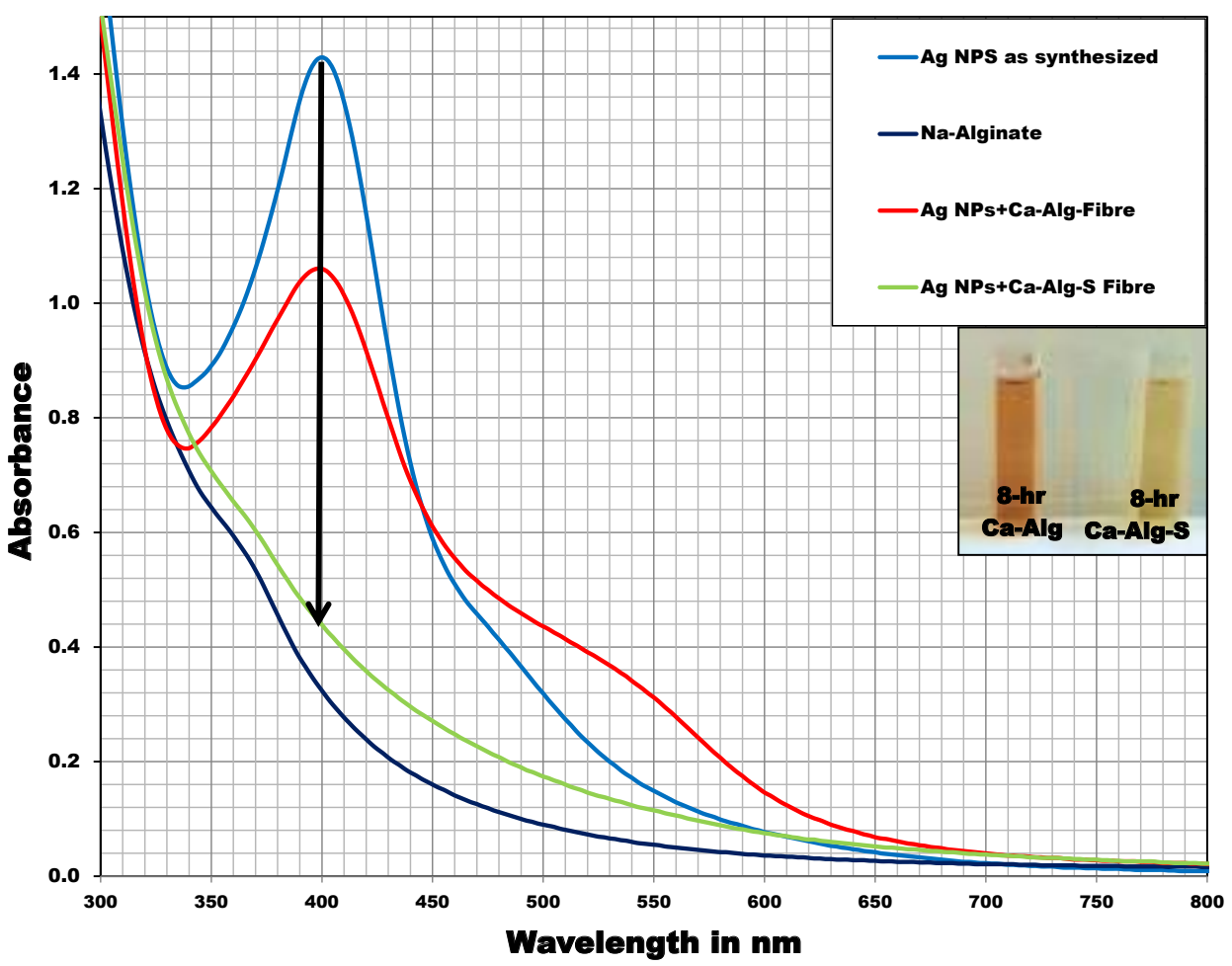

Fig. 4 Capture of Ag NPs by Ca-Alg and Ca-Alg-S studied via changes in absorbance of SPR signal at $400 \mathrm{~nm}$. After $8 \mathrm{~h}$ of Ca-Alg-S treatment, $90 \%$ capture of Ag NPs was achieved (green), evidenced by the disappearance of welldefined SPR of Ag NPs (blue). Ca-Alg treatment (without sulfur) led to an absorbance decrease of 34\% (red) and an increase in absorbance at $550 \mathrm{~nm}$, indicating a size increase/agglomeration. The presence of sulfur particle resulted in a significantly more effective capture of Ag NPs.

Table 1 Dimensions and loading of Ca-Alg and Ca-Alg-S and the respective Ag NP capture efficiency. Incorporation of sulfur particle enhanced capture efficiency by $60 \%$.

\begin{tabular}{lcr}
\hline Parameter/treatment & Ca-Alg Fibre & Ca-Alg-S Fibre \\
\hline S Particles Loading (\%wt) & 0.0 & 27.4 \\
Weight $(\mathrm{g})$ & 5.1 & 5.1 \\
Length (cm) & 213.4 & 214.1 \\
Average diameter (cm) & 0.148 & 0.148 \\
Total surface area (cm ${ }^{2}$ ) & 99.5 & 100.8 \\
Capture efficiency (\%)-8-h contact & 33.4 & 89.6 \\
Total Ag NPs removed (mg) & 20.6 & 247.0 \\
Capture efficiency (mg of Ag NPs/g of fibres) & 4.1 & 48.2 \\
\hline
\end{tabular}

After 80 minutes, anchoring event subsided and the diffusion of sulfur became the limiting step for the capture of residue Ag NPs, leading to a slower capture rate.

Table 1 shows the physical dimensions of $\mathrm{Ca}$ $\mathrm{Alg}$ and $\mathrm{Ca}-\mathrm{Alg}-\mathrm{S}$ and the respective Ag NP capture efficiency. Both $\mathrm{Ca}-\mathrm{Ag}$ and $\mathrm{Ca}-\mathrm{Alg}-\mathrm{S}$ produced are the same in terms of their lengths and diameters. Notably, a mere 34\% Ag NP capture was observed for Ca-Alg. With the presence of $27 \%$ wt sulfur par- ticles, Ca-Alg-S was able to remove/capture close to $90 \%$ of $\mathrm{Ag}$ NPs after $8 \mathrm{~h}$ of contact time under ambient condition without any agitation. This is highly significant when compared to the recent literature method involving sulfidation of $\mathrm{Ag}$ in which only $15 \%$ of $\mathrm{Ag}$ removal was achieved after $5 \mathrm{~h}$ of sulfidation of Ag NPs using acid volatile sulfide (AVS) [31]. AVS contents are relatively difficult to control as it relies on the actual composition of the wastewater used to produce AVS. Sulfides $\left(\mathrm{HS}^{-}\right.$and 
$\mathrm{S}^{2-}$ ) have also been used to capture Ag NPs, but they are toxic and environmental polluting, therefore the use of sulfur particles in the form of Ca-Alg-S offers a greener and safer option [32]. The Ca-Alg$S$ reported herewith has high potential for heavy metal nanoparticle removal, exemplified by the case study of Ag NPs presented in this report. As shown in Fig. S5, Ag NP capture led to a morphological change: white fibrous Ca-Alg-S gel became more compact and yellow in colour, and the changes served as signals to indicate the need to change to a new Ca-Alg-S gel which would constitute an advantage in real applications.

\section{CONCLUSION}

In summary, a new method capable of producing sulfur particles of $5.5 \pm 0.4 \mu \mathrm{m}$ in length, $3.9 \pm 0.4 \mu \mathrm{m}$ in width/thickness with an aspect ratio of 1.4 and good colloidal stability has been successfully developed under ambient conditions. A combination of a weak acid and sodium alginate allowed simultaneous controls of sulfur particle size and the imparting of colloidal stability in water with a high zeta potential of $-29.5 \mathrm{mV}$. Gelation of the alginate-protected sulfur particles with $\mathrm{CaCl}_{2}$ produced Ca-Alg-S fibrous gel with firmness suitable to be used as absorbent. Ag NPs were produced from microwaving a $\mathrm{AgNO}_{3}$ /sodium alginate mixture and used for capture efficiency study. Ca-Alg$\mathrm{S}$ gel outperformed Ca-Alg gel in capturing Ag NPs with the respective capture efficiency of $90 \%$ and $34 \%$, respectively, both of which are significantly better than the $15 \%$ reported for other literature sulfidation method. Ca-Alg-S fibrous gel has good potential in water treatment specifically for the removal of heavy metal particles including $\mathrm{Hg}, \mathrm{Cd}$, $\mathrm{Ni}$ and Pd. Being non-toxic and readily prepared under ambient conditions, Ca-Alg-S could be readily deployed in economically less-advanced rural areas where the high cost of nanofiltration remains a significant hinderance toward water purification.

\section{Appendix A. Supplementary data}

Supplementary data associated with this article can be found at http://dx.doi.org/10.2306/ scienceasia1513-1874.2021.S006.

Acknowledgements: The authors express their gratitude to the Ministry of Higher Education Malaysia for funding this work through the Fundamental Research Grant Scheme (Grant Number: FRGS/1/2017/STG07/TARUC/02/1).

\section{REFERENCES}

1. Wong PM, Juan JC, Lai JC, Lim TH (2020) Galvanic replacement-enabled synthesis of $\operatorname{In}(\mathrm{OH})_{3} / \mathrm{Ag} / \mathrm{C}$ nanocomposite as an effective photocatalyst for ultraviolet C degradation of methylene blue. ACS Omega 5, 13719-13728.

2. Syafiuddin A, Salmiati S, Hadibarata T, Kueh A, Salim M, Zaini M (2018) Silver nanoparticles in the water environment in Malaysia: Inspection, characterization, removal, modeling, and future perspective. Sci Rep 8, ID 986.

3. Yu H, Stapleton A, Lewis D, Wang L (2017) High performance flexible metal oxide/silver nanowire based transparent conductive films by a scalable lamination-assisted solution method. $J$ Materiomics 3, 77-82.

4. Yu S, Yin Y, Liu J (2013) Silver nanoparticles in the environment. Environ Sci Process Impacts 15, 78-92.

5. Khatoon U, Nageswara Rao G, Mohan K, Ramanaviciene A, Ramanavicius A (2017) Antibacterial and antifungal activity of silver nanospheres synthesized by tri-sodium citrate assisted chemical approach. Vacuum 146, 259-265.

6. Balavijayalakshmi J, Ramalakshmi V (2017) Carica papaya peel mediated synthesis of silver nanoparticles and its antibacterial activity against human pathogens. J Appl Res Technol 15, 413-422.

7. Khodashenas B, Ghorbani H (2019) Synthesis of silver nanoparticles with different shapes. Arabian $J$ Chem 12, 1823-1838.

8. McGillicuddy E, Morrison L, Cormican M, Dockery P, Morris D (2018) Activated charcoal as a capture material for silver nanoparticles in environmental water samples. Sci Total Environ 645, 356-362.

9. Nam S, Hillyer M, Condon B, Lum J, Richards M, Zhang Q (2020) Silver nanoparticle-infused cotton fiber: Durability and aqueous release of silver in laundry water. J Agric Food Chem 68, 13231-13240.

10. Peng M, Yu X, Guan Y, Liu P, Yan P, Fang F, Guo J, Chen $Y$ (2019) Underlying promotion mechanism of high concentration of silver nanoparticles on anammox process. ACS Nano 13, 14500-14510.

11. Benn T, Westerhoff P (2008) Nanoparticle silver released into water from commercially available sock fabrics. Environ Sci Technol 42, 4133-4139.

12. Zhang C, Jiang $H$, Gu S, Zhou $X$, Lu Z, Kang X, Yin L, Huang J (2019) Combination analysis of the physiology and transcriptome provides insights into the mechanism of silver nanoparticles phytotoxicity. Environ Pollut 252, 1539-1549.

13. Tripathi D, Tripathi A, Shweta Singh S, Singh Y, Vishwakarma K, Yadav G, Sharma S, Singh V, et al. (2017) Uptake, accumulation and toxicity of silver nanoparticle in autotrophic plants, and heterotrophic microbes: A concentric review. Front Microbiol 8, 7.

14. Abramenko N, Demidova T, Abkhalimov E, Ershov B, 
Krysanov E, Kustov L (2018) Ecotoxicity of differentshaped silver nanoparticles: Case of zebrafish embryos. J Hazard Mater 347, 89-94.

15. Fu C, Horng J, Tong S, Cherng B, Liao B, Lin L, Chou M (2020) Exposure to silver impairs learning and social behaviors in adult zebrafish. $J$ Hazard Mater 403, ID 124031.

16. Carlson C, Hussain S, Schrand A, K Braydich-Stolle L, Hess K, Jones R, Schlager J (2008) Unique cellular interaction of silver nanoparticles: Size-dependent generation of reactive oxygen species. $J$ Phys Chem B 112, 13608-13619.

17. Ferdous Z, Nemmar A (2020) Health impact of silver nanoparticles: A review of the biodistribution and toxicity following various routes of exposure. Int $J$ Mol Sci 21, ID 2375.

18. Mao B, Chen Z, Wang Y, Yan S (2018) Silver nanoparticles have lethal and sublethal adverse effects on development and longevity by inducing ROS-mediated stress responses. Sci Rep 8, ID 2445.

19. Akter M, Sikder M, Rahman M, Ullah A, Hossain K, Banik S, Hosokawa T, Saito T, et al (2018) A systematic review on silver nanoparticles-induced cytotoxicity: physicochemical properties and perspectives. $J$ Adv Res 9, 1-16.

20. Gicheva G, Yordanov G (2013) Removal of citratecoated silver nanoparticles from aqueous dispersions by using activated carbon. Colloid Surf A Physiochem Eng Asp 431, 51-59.

21. Okello V, Du N, Deng B, Sadik O (2011) Environmental applications of poly(amic acid)-based nanomaterials. J Environ Monit 13, 1236-1245.

22. McGillicuddy E, Murray I, Kavanagh S, Morrison L, Fogarty A, Cormican M, Dockery P, Prendergast M, et al (2017) Silver nanoparticles in the environment: Sources, detection and ecotoxicology. Sci Total Environ 575, 231-246.

23. Wang Y, Xu Z, Xu L (2020) High efficient removal of silver nanoparticles by coagulation with tetraethylenepentamine modified silica. Colloid Surf A Physiochem Eng Asp 599, ID 124897.

24. Liang H, Wang L, Chen P, Lin H, Chen L, He D, Yu $S$ (2010) Carbonaceous nanofiber membranes for selective filtration and separation of nanoparticles. Adv Mater 22, 4691-4695.

25. Wang Z, Wang Z, Lin S, Jin H, Gao S, Zhu Y, Jin J (2018) Nanoparticle-templated nanofiltration membranes for ultrahigh performance desalination. Nat Commun 9, 1-9.

26. Liu G, Jiang J, Yu R, Yan H, Liang R (2020) Silver nanoparticle-incorporated porous renewable film as low-cost bactericidal and antifouling filter for pointof-use water disinfection. Ind Eng Chem Res 59, 10857-10867.
27. Budi S, Suliasih B, Rahmawatia I, Erdawati E (2020) Size-controlled chitosan nanoparticles prepared using ionotropic gelation. ScienceAsia 46, 457-461.

28. Gao C, An Q, Xiao Z, Zhai S, Zhai B, Shi Z (2017) Highly recyclable Ag NPs/alginate composite beads prepared via one-pot encapsulation method for efficient continuous reduction of p-nitrophenol. New $J$ Chem 41, 13327-13335.

29. Fernando I, Lee W, Han E, Ahn G (2020) Alginatebased nanomaterials: Fabrication techniques, properties, and applications. Chem Eng J 391, ID 123823.

30. Tripathi R, Rao R, Tsuzuki T (2018) Green synthesis of sulfur nanoparticles and evaluation of their catalytic detoxification of hexavalent chromium in water. RCS Adv 8, 36345-36352.

31. Kaegi R, Voegelin A, Ort C, Sinnet B, Thalmann B, Krismer J, Hagendorfer H, Elumelu M, et al (2013) Fate and transformation of silver nanoparticles in urban wastewater systems. Water Res 47, 3866-3877.

32. Reinsch B, Levard C, Li Z, Ma R, Wise A, Gregory K, Brown G, Lowry G (2012) Sulfidation of silver nanoparticles decreases Escherichia coli growth inhibition. Environ Sci Technol 46, 6992-7000.

33. Roach K, Stefaniak A, Roberts J (2019) Metal nanomaterials: Immune effects and implications of physicochemical properties on sensitization, elicitation, and exacerbation of allergic disease. $J$ Immunotoxicol 16, 87-124.

34. Wręczycki J, Bieliński D, Anyszka R (2018) Sulfur/organic copolymers as curing agents for rubber. Polymers 10, ID 870.

35. Zhao X, Li Q, Ma X, Xiong Z, Quan F, Xia Y (2015) Alginate fibers embedded with silver nanoparticles as efficient catalysts for reduction of 4-nitrophenol. RSC Adv 5, 49534-49540.

36. Xu P, Cen C, Chen N, Lin H, Wang Q, Xu N, Tang J, Teng Z (2018) Facile fabrication of silver nanoparticles deposited cellulose microfiber nanocomposites for catalytic application. J Colloid Interface Sci 526, 194-200.

37. Zhu Y, Chen F (2014) Microwave-assisted preparation of inorganic nanostructures in liquid phase. Chem Rev 114, 6462-6555.

38. Levard C, Mitra S, Yang T, Jew A, Badireddy A, Lowry G, Brown G (2013) Effect of chloride on the dissolution rate of silver nanoparticles and toxicity to E. coli. Environ Sci Technol 47, 5738-5745.

39. Sadovnikov S, Gusev A (2017) Recent progress in nanostructured silver sulfide: From synthesis and nonstoichiometry to properties. J Mater Chem A 5, 17676-17704. 


\section{Appendix A. Supplementary data}

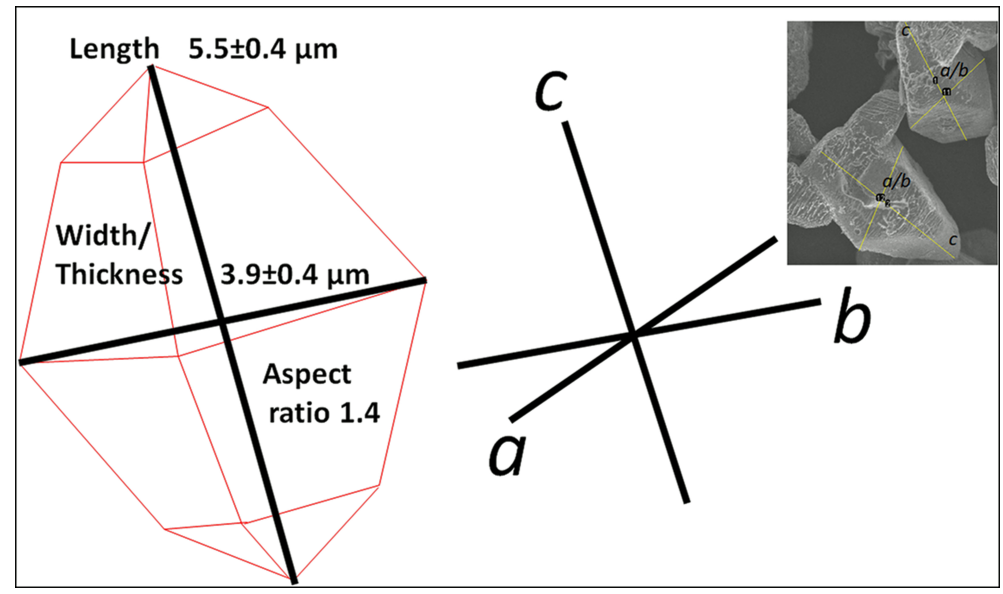

Fig. S1 The sizes of the slightly anisotropic sulfur particles were described using length and width/thickness measurements. Length values were measured from point-to-point along the $c$-axis while values of width/thickness along $a$-axis or $b$-axis. Note: Width and thickness are considered the same due to symmetry. Measurements were carried out using software ImageJ after calibration.

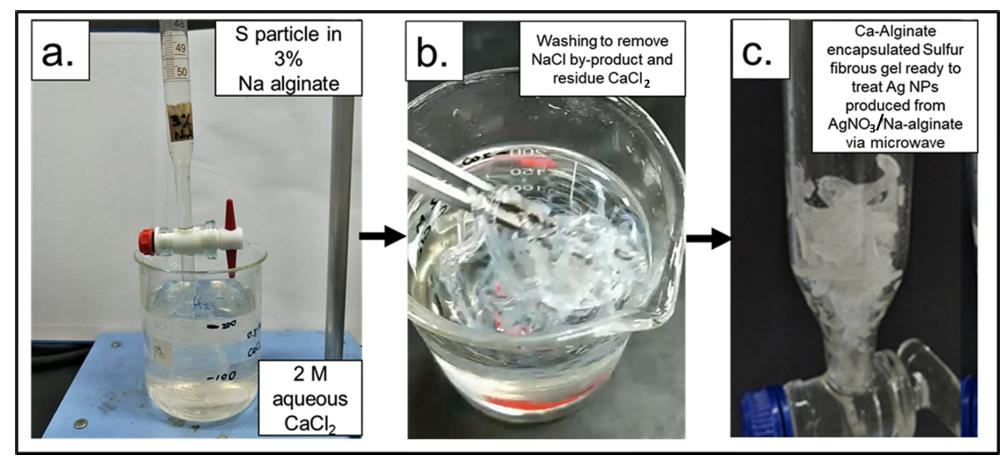

Fig. S2 Preparation of calcium alginate-encapsulated sulfur particle fibrous gel (Ca-Alg-S).

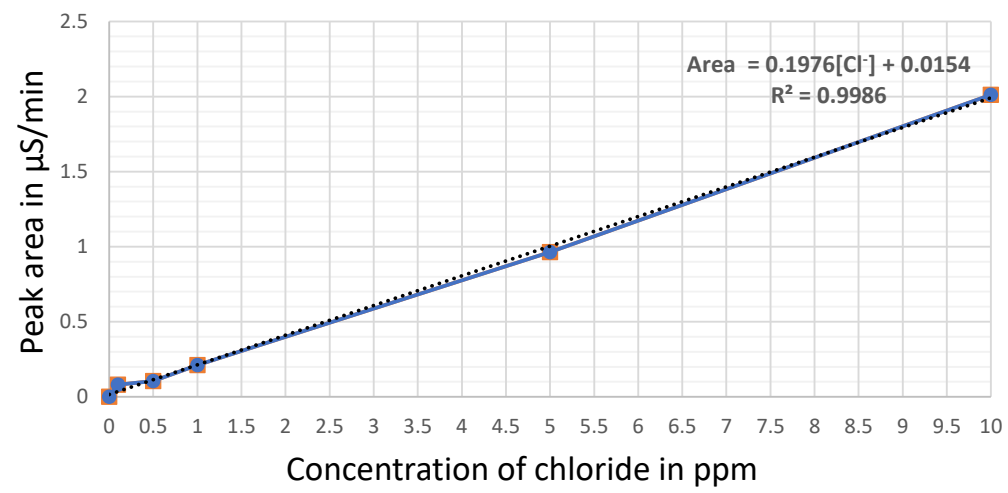

Fig. S3 A linear relationship between $\mathrm{Cl}^{-}$concentration in ppm and area of peaks observed in Ion chromatography (Dionex ICS-1000), indicating reliable confirmation of removal of $\mathrm{Cl}^{-}$in Ca-Alg and Ca-Alg-S prior to capture of Ag NPs. 


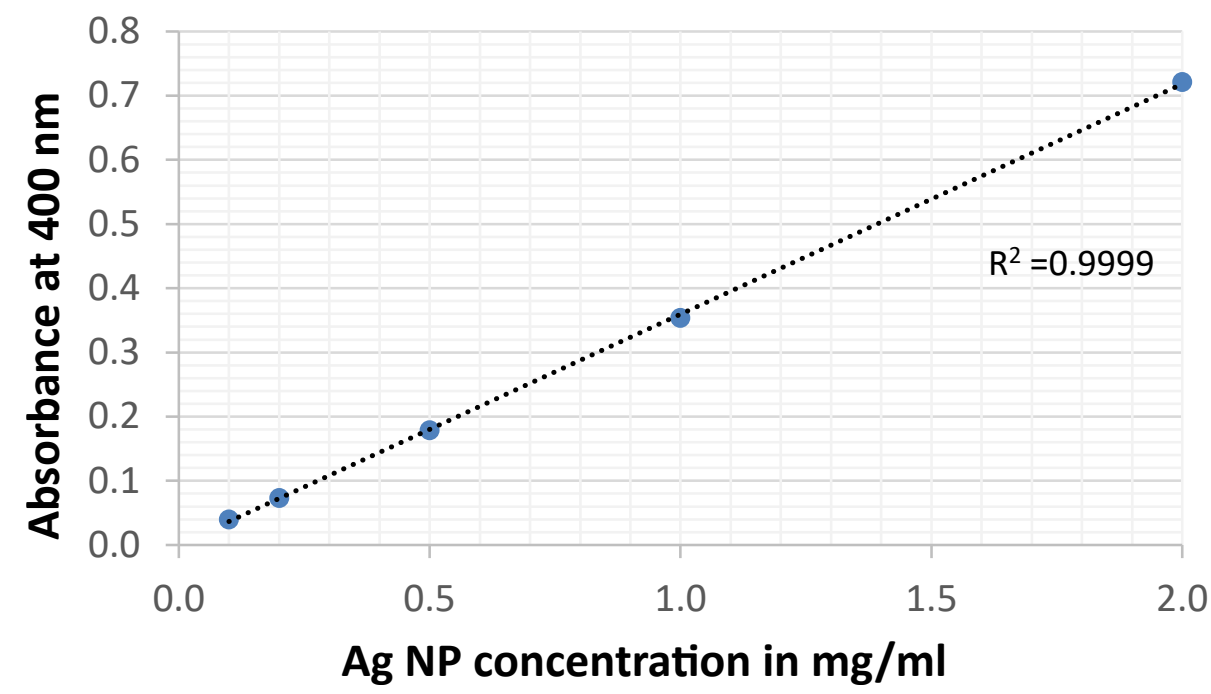

Fig. S4 A linear relationship between Ag NP concentration in $\mathrm{mg} / \mathrm{ml}$ and absorbance at $400 \mathrm{~nm}$ (SPR band), indicating a good agreement in the mass of Ag NPs captured.

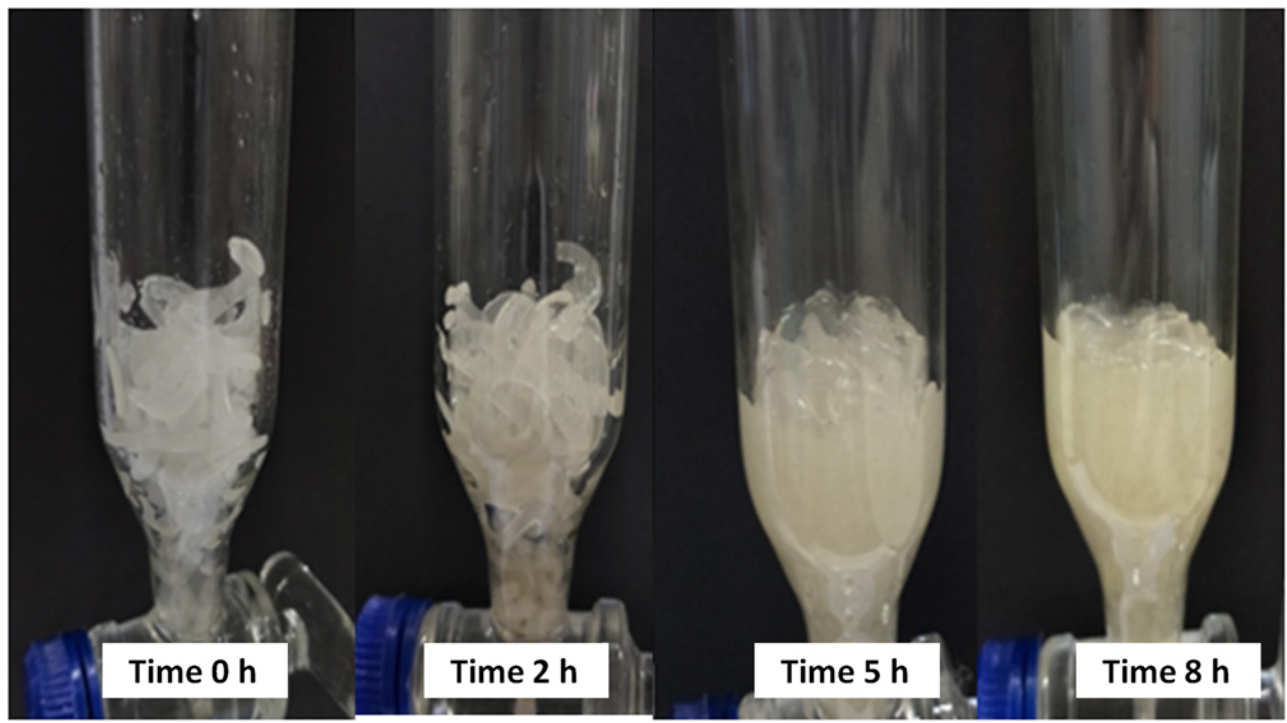

Fig. S5 Semi-transparent white fibrous Ca-Alg-S gel as prepared before Ag NP capture (time $=0 \mathrm{~h}$ ). Gradual changes in gel morphology and colour were observed after Ag NP capture especially after $8 \mathrm{~h}$ of contact. The initial fibrous Ca-Alg-S turned completely into a more compact gel with the space between fibres diminished. This served as a visual signal that a new gel should be used for subsequent Ag NP capture. Gradual yellowing of the gel is consistent with Ag $\mathrm{NP}$ capture and the formation of $\mathrm{Ag}_{2} \mathrm{~S}$. 